\title{
Remembering Robert Venturi, a Modern Mannerist
}

In Memoriam / THEORY

\section{Maurizio Sabini}

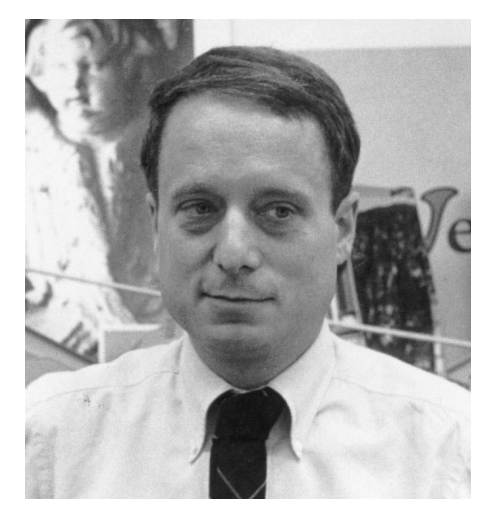

After the generation of the "founders" of the Modern Movement, very few architects had the same impact that Robert Venturi had on architecture and the way we understand it in our post-modern era. Aptly so and with a virtually universal consensus, Vincent Scully called Complexity and Contradiction in Architecture (1966) "probably the most important writing on the making of architecture since Le Corbusier's Vers une architecture, of 1923." 'And I would submit that no other book has had an equally consequential impact ever since, even though Learning from Las Vegas (published by Venturi with Denise Scott Brown and Steven Izenour in 1972) has come quite close. As Aaron Betsky has observed:

Like the Modernism that Venturi sought to nuance and enrich, many of the elements for which he argued were present in even the most reduced forms of high Modernism. Venturi was trying to save Modernism from its own pronouncements more than from its practices. To a large extent, he won, to the point now that we cannot think of architecture since 1966 without reference to Robert Venturi. ${ }^{2}$ 


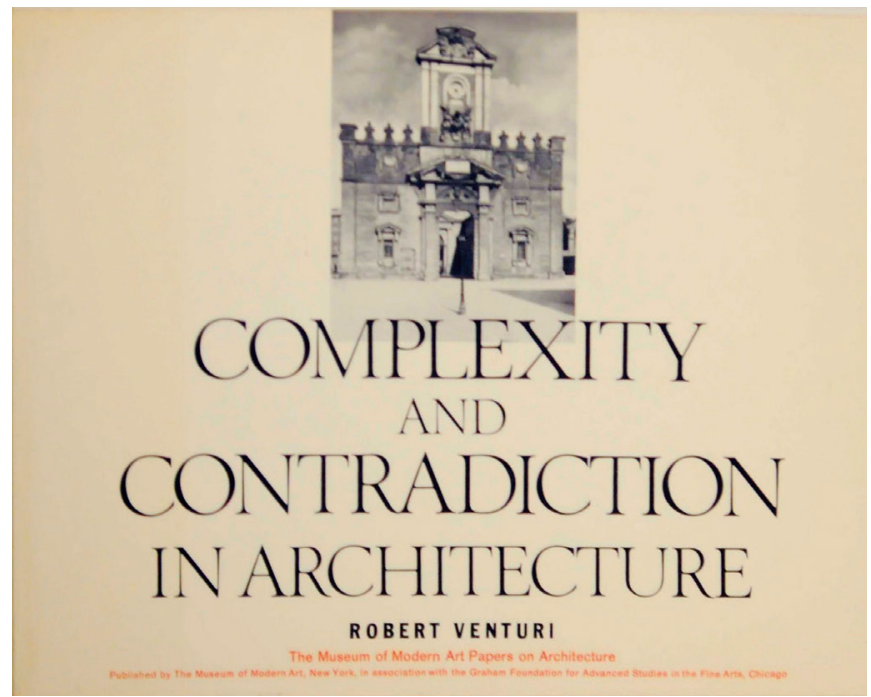

Figure 1. Robert Venturi, Complexity and Contradiction in Architecture (London: The Architectural Press, with the Museum of Modern Art, New York, 1977; or. ed., New York: The Museum of Art, 1966).

Venturi's inquiry program was very clear (and complex at the same time): first an understanding of the complexity of how architectural form comes about and then the role of symbolism in the design process. With his two early books Venturi did just that, with unsurpassed critical acumen, intellectual clarity, scholarly soundness and agility, and artistic sensibility (as well as his typical wit). Learning from Las Vegas (LLV), much more misunderstood and less universally accepted than its prequel, was indeed a natural development of the same line of inquiry taking off from where Complexity and Contradiction $(C \& C)$ had left:

Is not Main Street almost all right?... [...] it is perhaps from the everyday landscape, vulgar and disdained, that we can draw the complex and contradictory order that is valid and vital for our architecture as an urbanistic whole. ${ }^{3}$

While working at the Italian translation of $L L V$ (done in collaboration with Venturis' dear friend and colleague from Milan, the late Margherita Rossi Paulis), I had the privilege of getting to know up close Robert Venturi and Denise Scott Brown, who both thoroughly discussed and oversaw that edition of their book. I cannot underscore enough the intellectual and personal growth that their precious friendship, continued over the years after that endeavor, ${ }^{4}$ was able to offer me. Venturi was an incredibly pleasant person to be around, a gentleman of another era, whose polite and measured manners and bearing were in sharp contrast with the radicality of his ideas (not surprisingly, another example of "complexity and contradiction"...). Through the many conversations we had, on and beyond the translation of the book, I was struck by his stunning knowledge of architectural history, the rapidity 

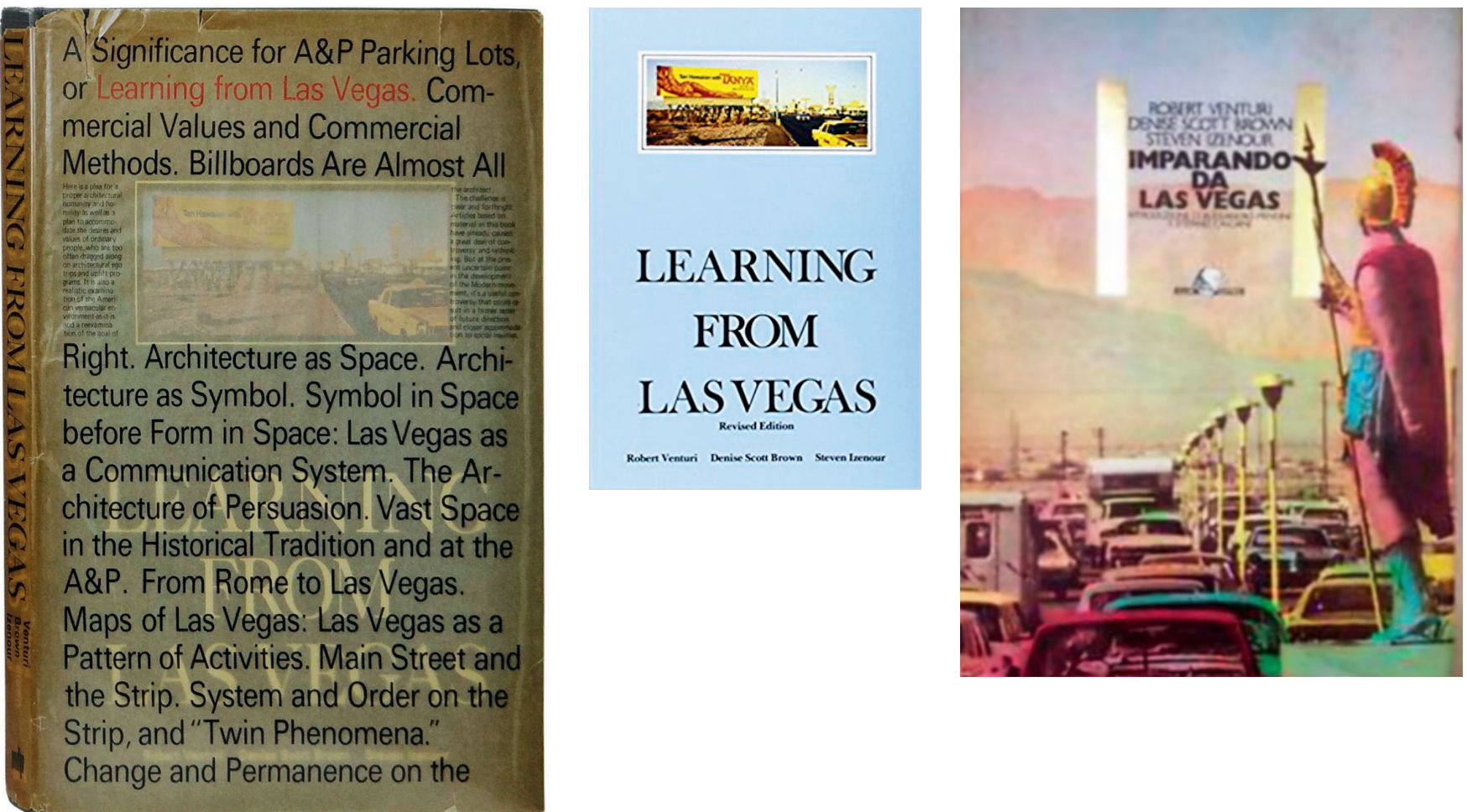

Figure 2. Left: Robert Venturi, Denise Scott Brown and Steven Izenour, Learning from Las Vegas (Cambridge, MA, USA: The MIT Press, 1972 - or. ed.). Center: Learning from Las Vegas (The MIT Press, 1977 - 2nd ed.). Right: Imparando da Las Vegas (Venice, It.: Cluva Editrice, 1985 - 1st Italian ed.).

of his intellectual and aesthetic judgment (curiously akin to his quick way of sketching, typically with markers on trace), his genuine interest for any example of good architecture (beyond ideologies or over-constructed theories), be it by Michelangelo, John Soane, Alvar Aalto, or from the Italian countryside or the New England. Or by Giuseppe Vaccaro, whose church in Recoaro (Italy, 1951) which Bob loved - I came to know during a memorable field trip that Bob and Denise wanted to take, along with a group of friends and younger colleagues (including Margherita and her husband and partner Franco Paulis, and Vaccaro's daughter Carolina). The occasion was offered during one of their summer vacations that Bob and Denise used to spend in Venice in the mid-80s, with their son Jimmy.

Venturi has been mistakenly identified as the "father" (or "grandfather," depending on the points of view) of Post-Modernism, a label that he, along with Denise Scott Brown, has repeatedly rejected. Sure, Post-Modernism was one of the outcomes of their inquiries and work, but an unwanted one. As Denise has pointed out several times:

PoMo [Post-Modernist] architects handled history by imitation and with insufficient knowledge... we are postmodernists, but only in the early 1960 s sense ... which talked about the end of innocence after the 
Holocaust, about multiculturalism, about reserving judgment, about being skeptical even about your own best ideas - that [Post-Modern mentality] we very much agree with." 5

Through the richness of their works, Venturi and Scott Brown have been the catalysts for various strands of research in contemporary architecture, including, yes (though unwittingly) Post-Modernism, but also Critical Regionalism (another example of a "both-and" phenomenon, an aspect of architecture dear to VSB), or a growing interest into popular culture and the impact of architecture and urbanism on a global scale (hence, i.e., Rem Koolhaas' continued interest in $L L V^{6}$ ).

While Bob and Denise were uncomfortable with the "neo-Modernists," superficially re-proposing in the second half of the twentieth century a formal vocabulary of architecture for a society and culture that had dramatically changed since the times of the Modern Movement, Venturi had a great admiration for the original Modernists. In fact, not long ago, he famously retracted one of his most celebrated witty mottos, "less is a bore,"
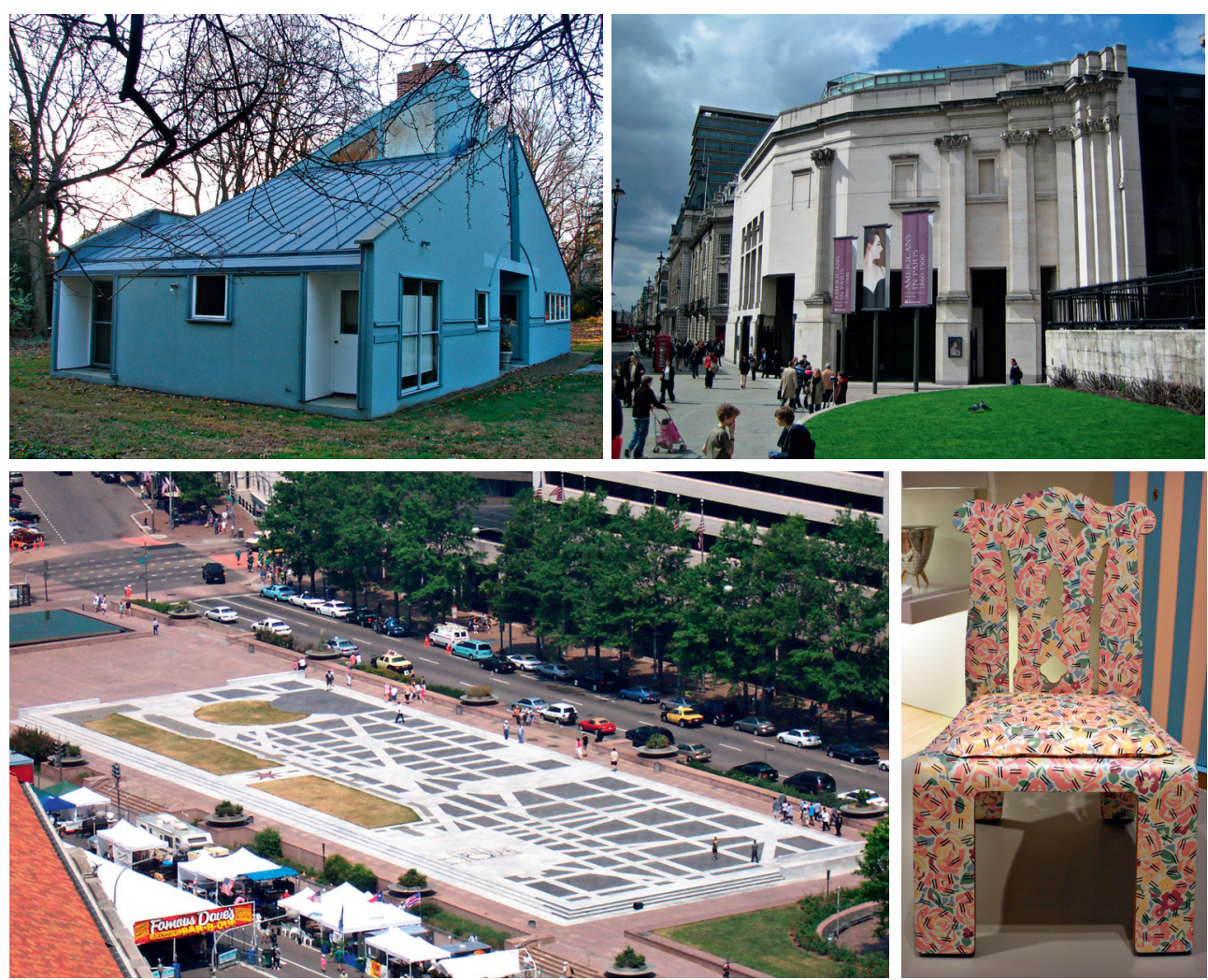

Figure 3. Clockwise, from top left: V\&R, Vanna Venturi House, Chestnut Hill, Philadelphia, 1964; VRSB, Sainsbury Wing, National Gallery, London, 1991; VRSB, Knoll International Furniture Collection, Chippendale Chair with "Grandmother Motif," 1984; VRSB, Freedom Plaza (formerly Western Plaza), Pennsylvania Avenue, Washington DC, 1980 - the realized version, while retaining the overall vision, somewhat departed from VRSB's initial design. (V\&R: Venturi and Rauch, 1964-69; VRSB: Venturi Rauch \& Scott Brown, 1969-89 - the firm was renamed Venturi, Scott Brown and Associates [VSBA] in 1989, and VSBA Architects \& Planners LLC in 2012.) 


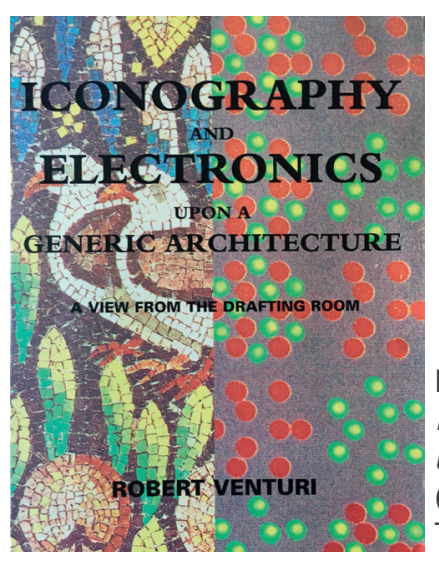

Figure 4. Robert Venturi, Iconography and Electronics upon a Generic Architecture (Cambridge, MA, USA: The MIT Press, 1996).

as he reaffirmed his appreciation and admiration for the work of Mies ("the only thing that I regret having said - and I said many!"). ${ }^{7}$

What Venturi was interested in was a kind of "Modern Mannerism," re-living a condition (under new historical circumstances) of one of his favorite architects of all times, Michelangelo. Through the many works of architecture and design at all scales (from the Vanna Venturi House and the National Gallery Sainsbury Wing in London, to the tea set for Alessi, the chairs for Knoll, Freedom Plaza in Washington DC and the campus planning for the University of Michigan), always developed in collaboration with Denise Scott Brown and their teams, Venturi has strived to explore and

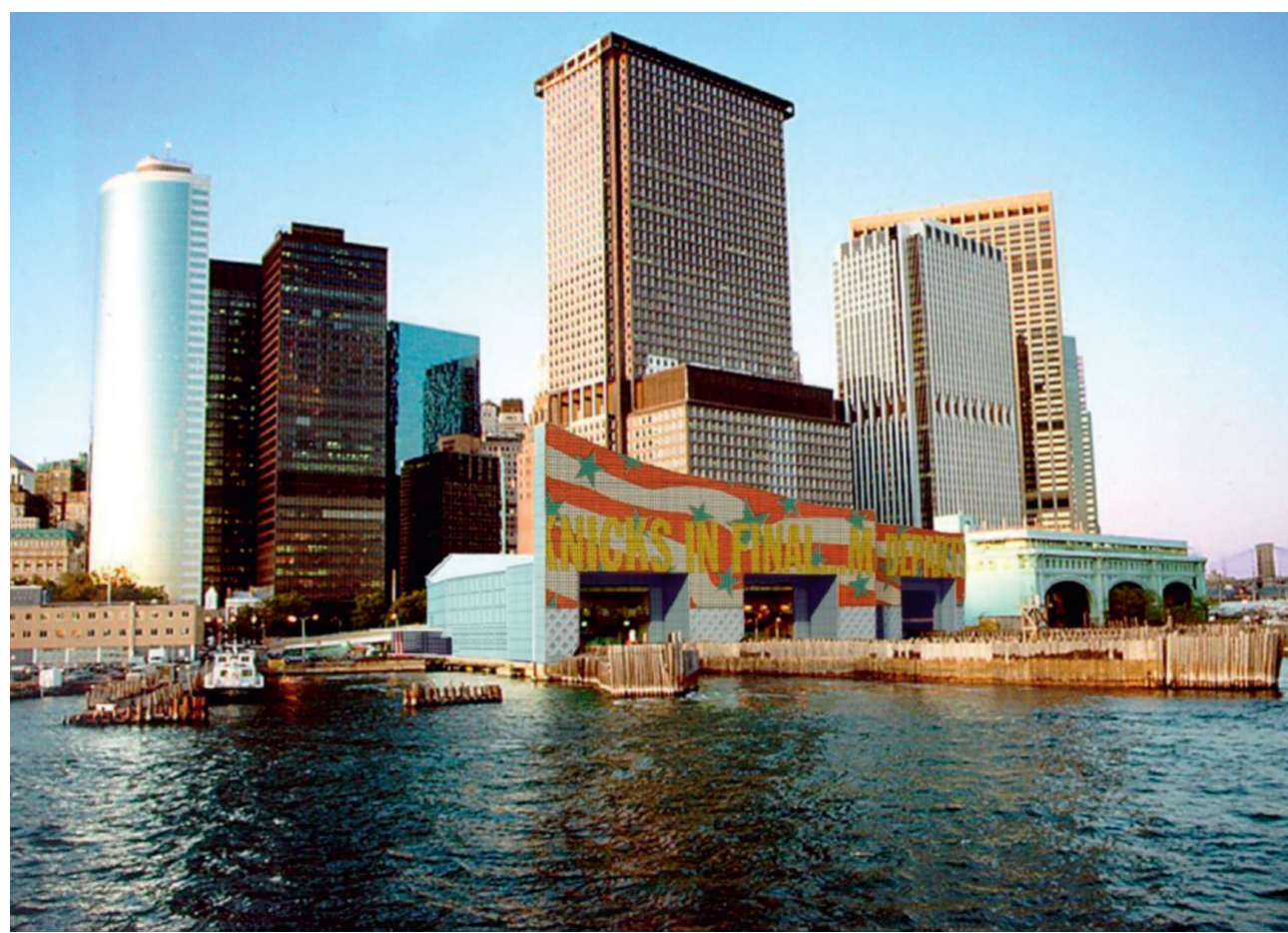

Figure 5. VSBA, Whitehall Ferry Terminal (unbuilt), Lower Manhattan, New York, 1995. 
stretch the limits of the Modern paradigm, navigating the difficult territory of meaning, symbolism and communication, without falling into pop mockery and superficial historicism. He wanted to be "relevant," as an architect understanding popular culture, while operating in the "electronic age."

Consistently enough, his last important book Iconography and Electronics upon a Generic Architecture (1996), ${ }^{8}$ which is often overlooked, has further developed his ideas from the more famous books of the $60 \mathrm{~s}$ and $70 \mathrm{~s}$. In what seems to be the logical conclusion of a trajectory of inquiry into the themes of form, symbolism and meaning, Venturi clarified his vision of "architecture as communication," by drawing inspiration from the Byzantine mosaics (especially in Ravenna, Italy), which were used to communicate religious stories - actually one story, that one of the Catholic Church. Similarly, he argued, we can communicate now through electronic media the many stories and varied information of our multi-cultural, complex and pluralistic society. The VSBA project (unfortunately unbuilt) for the Whitehall Ferry Terminal in Lower Manhattan remains perhaps the most significant design expression of the ideas elaborated in I\&E. From Rome $(C \& C)$, to Las Vegas ( LLV), to Ravenna (I\&E)... and back to New York.

Modern Mannerism was certainly a notion that Venturi would have subscribed to, even though he and Denise have been always uncomfortable with the limitations that any categorization inevitably brings along. Always critical towards formulaic or over-theorized approaches, Venturi and Scott Brown have consistently developed and applied a pragmatic design philosophy that analyzes and leverages (in an inclusive way) all the constitutive elements and aspects of the specific reality - cultural (popular and not), contextual, and disciplinary - which the design is called to represent, interpret and comment on (surely, with a "mannerist" artistic sensibility). ${ }^{9}$

As I had the opportunity to write on the occasion of an exhibition on the Sainsbury Wing project at the Fondazione Masieri in Venice, ${ }^{10} \mathrm{I}$ remember Robert Venturi stating clearly and simply (but profoundly) during a symposium held at Columbia University in April 1986: "more than anything, I want to be appropriate." He wanted appropriately to be a Modern Mannerist (while calling us all to critically reflect and practice, in our own ways), for an architecture of communication in the post-modern era. And as such we should remember him and treasure his legacy.

\section{Notes}

1. Vincent Scully, "Introduction," in Robert Venturi, Complexity and Contradiction in Architecture (London: The Architectural Press, with the Museum of Modern Art, New York, 1977; or. ed., New York: The Museum of Art, 1966), 9.

2. Aaron Betsky, "Learning from Robert Venturi," Architect, September 20, 2018, https://www.architectmagazine.com/design/learning-from-robert-venturi_o.

3. Venturi, Complexity and Contradiction, 104. 
4. Both Robert Venturi and Denise Scott Brown have always highly appreciated the first Italian edition of the book, which Venturi, in particular, did not want to be "outlandish" that was the term that he insistently used, with his typical keen interest to always find the appropriate word to convey his ideas. Our thanks to Manuel Orazi of the publisher Quodlibet, Macerata (Italy), for having recently republished that Italian translation, although under a different graphic layout and a slightly different title: Imparare da Las Vegas, ed. Manuel Orazi (Macerata, It.: Quodlibet, 2010).

5. Denise Scott Brown at the "Architecture after Las Vegas" symposium (January 21-23, 2010), on the occasion of the major retrospective exhibition "What We Learned: The Yale Las Vegas Studio and the Work of Venturi Scott Brown \& Associates," October 29, 2009 February 5, 2010, School of Architecture, Yale University, New Haven, CT (USA).

6. "Re-Learning from Las Vegas," interview with Robert Venturi and Denise Scott Brown by Rem Koolhaas and Hans Ulrich Obrist, in AMOMA, Rem Koolhaas \& Others, Content (Cologne, Ger.: Taschen, 2004), 150-57.

7. Personal recollection.

8. Robert Venturi, Iconography and Electronics upon a Generic Architecture (Cambridge, MA, USA: The MIT Press 1996).

9. See Robert Venturi, "A New Mannerism, for Architecture as Sign," in Robert Venturi \& Denise Scott Brown, Architecture as Signs and Systems for a Mannerist Time (Cambridge, MA, USA: The Belknap Press of Harvard University Press, 2004), 73-100. The book, one of the latest writings by Venturi \& Scott Brown, is based on the William E. Massey Sr. Lectures in the History of American Civilization that they both gave at Harvard in 2003.

10. Maurizio Sabini, "Da Las Vegas a Londra: per un'architettura appropriata," Phalaris 17 (1988): 13. Phalaris was the journal/organ of the Fondazione Masieri: both the journal and the Fondazione were directed by Luciano Semerani, professor at the Istituto Universitario di Architettura di Venezia. See also on the same issue of Phalaris, Robert Venturi's piece: "Dall' invenzione alla convenzione in architettura [From Invention to Convention in Architecture]," 3-9, transcript of a lecture on the Sainsbury Wing project, previously delivered, and Carolina Vaccaro's "Tre musei di VRSB," 10-12. The exhibition on the project. (which was just underway to be realized) ran from May 21, till July 2, 1988, and was cocurated by Evelina Francia and myself.

\section{Credits}

Figures 1, 2, 4: Images by the Author.

Figures 3 and 5: Images retrieved from Wikimedia Commons. 